Case Report

\title{
Kytococcus schroeteri Bacteremia in a Patient with Hairy Cell Leukemia: A Case Report and Review of the Literature
}

\author{
Akshay Amaraneni, ${ }^{1}$ Devin Malik, ${ }^{1}$ Sakshi Jasra, ${ }^{2}$ \\ Sreenivasa R. Chandana, ${ }^{3}$ and Deepak Garg ${ }^{1}$ \\ ${ }^{1}$ Department of Internal Medicine, Western Michigan University Homer Stryker M.D. School of Medicine, \\ 1000 Oakland Drive, Kalamazoo, MI 49008, USA \\ ${ }^{2}$ Department of Internal Medicine, University at Buffalo School of Medicine, Buffalo, NY 14260, USA \\ ${ }^{3}$ Department of Hematology and Oncology, West Michigan Cancer Center, 200 N. Park Street, Kalamazoo, MI 49007, USA
}

Correspondence should be addressed to Akshay Amaraneni; akshay.amaraneni@med.wmich.edu

Received 21 February 2015; Accepted 23 April 2015

Academic Editor: Alexandre R. Marra

Copyright (C) 2015 Akshay Amaraneni et al. This is an open access article distributed under the Creative Commons Attribution License, which permits unrestricted use, distribution, and reproduction in any medium, provided the original work is properly cited.

\begin{abstract}
The Kytococcus genus formerly belonged to Micrococcus. The first report of a Kytococcus schroeteri infection was in 2002 in a patient diagnosed with endocarditis. We report a case of central line associated Kytococcus schroeteri bacteremia in a patient with underlying Hairy Cell Leukemia. Kytococcus schroeteri is an emerging infection in the neutropenic population and in patients with implanted artificial tissue. It is thought to be a commensal bacterium of the skin; however, attempts to culture the bacteria remain unsuccessful. There have been a total of 5 cases (including ours) of $K$. schroeteri bacteremia in patients with hematologic malignancies and neutropenia and only 18 documented cases in any population. Four of the cases of bacteria in neutropenic patients have been fatal, but early detection and treatment could make a difference in clinical outcomes.
\end{abstract}

\section{Introduction}

Kytococcus schroeteri was first identified in 2002 in a patient with endocarditis and bacteremia [1]. The Kytococcus genus formerly belonged to Micrococcus and was recently changed due to chemotaxonomic and phylogenetic grouping [1]. To date, there have been few situations where Kytococcus species have been pathogenic [2-6]. Patients with hematologic malignancies are immunocompromised and are prone to opportunistic infections from nonharmful bacteria. Here, we report a rare case of Kytococcus schroeteri sepsis in a patient with Hairy Cell Leukemia.

\section{Case Report}

A fifty-year-old Caucasian woman presented with fever, malaise, and pancytopenia. Her surgical history was significant for a splenectomy following a motor vehicle accident several years ago, and her vaccination status was up to date. Bone marrow biopsy revealed a diagnosis of Hairy Cell Leukemia. Immunophenotyping by flow cytometry was positive for CD11c, CD25, CD103, CD19, and CD20. The patient was started on Cladribine (2-chlorodeoxyadenosine), a purine analog, $0.14 \mathrm{mg} / \mathrm{kg} / \mathrm{day}$, for a five-day course. Chemotherapy was administered through a central venous catheter. While receiving Cladribine, the patient was noted to have persistent fevers with stable hemodynamics. After carefully excluding infectious etiologies of her persistent fever intravenous Cefepime was changed to oral ciprofloxacin and prophylactic fluconazole. Upon discharge, blood and sputum cultures were negative for bacteria.

One week later, she presented with persistent fevers and dyspnea. She was intubated and transferred to the Intensive Care Unit. Chest X-ray showed a left lower lobe infiltrate. She was started on vancomycin, piperacillin/tazobactam, and levofloxacin for healthcare associated pneumonia in the 


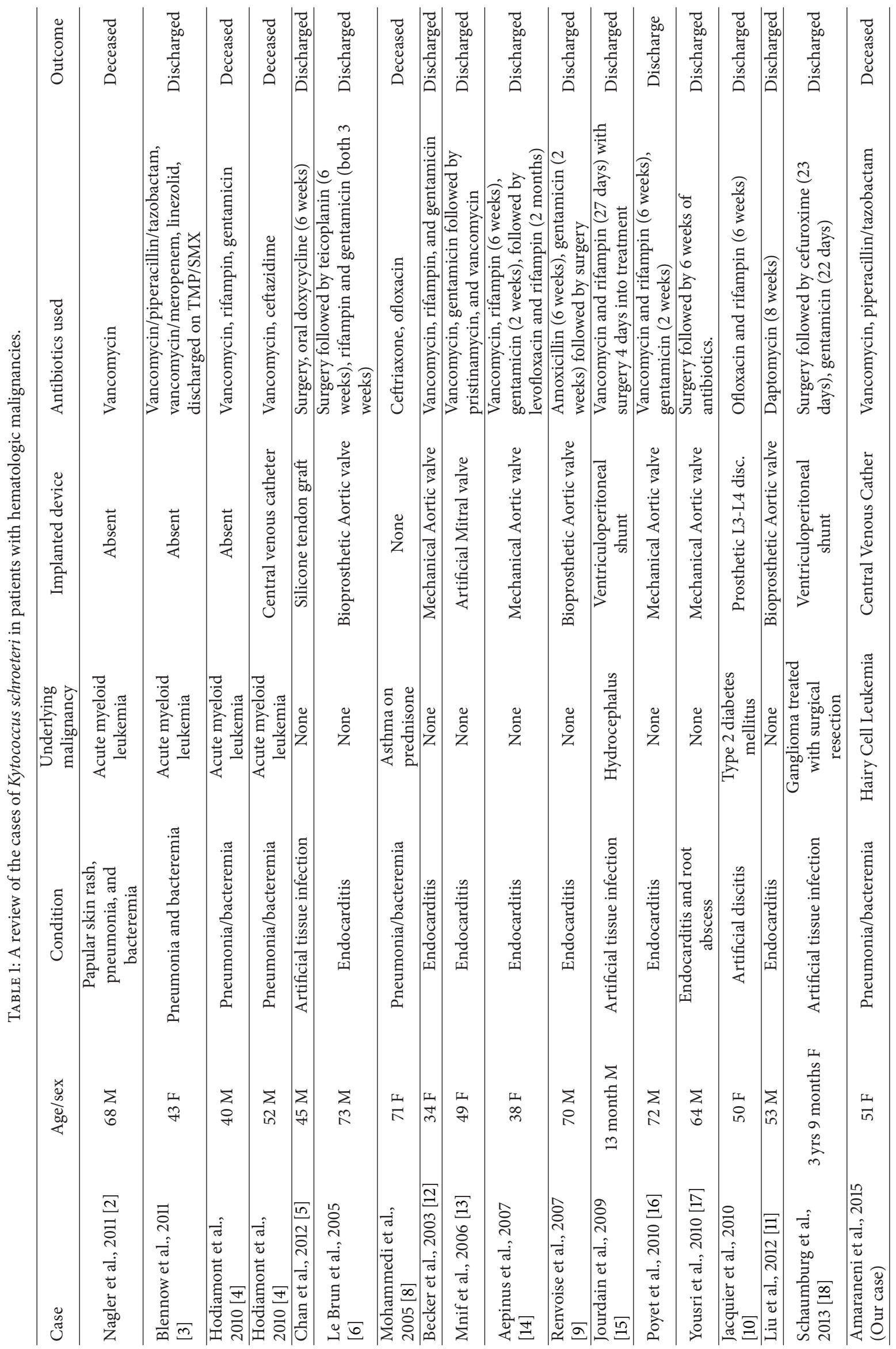


setting of neutropenic fever. Liposomal amphotericin-B was also added for broad-spectrum antifungal coverage as she was at high risk for developing fungal infection.

Bronchoscopy, performed at bedside, revealed diffuse petechial lesions in the airway. Bronchoalveolar lavage (BAL) culture grew greater than 10,000 colonies of a gram-positive organism that grew in clusters but was neither Staphylococcus aureus nor coagulase negative Staphylococcus when tested by fluorescent in situ hybridization using peptide nucleic acid probes (PNA FISH). The patient's blood cultures were also positive for the same nonstaphylococcal gram-positive bacteria in two separate aerobic culture tubes. Because the bacterium was unidentified, the patient remained on vancomycin. However, despite aggressive treatment, the patient deteriorated and expired four days after hospitalization. Our facility could not identify the bacteria and the sample was sent to the Department of Community Health of Michigan. The isolate was identified via sequencing of the $16 \mathrm{~S}$ rDNA segment as Kytococcus schroeteri. Because the bacterium was detected posthumously, no susceptibility testing was performed by our facility and no samples were available to perform testing after the bacterium was identified.

\section{Discussion}

$K$. schroeteri is a recently discovered member of the genus Kytococcus that is thought to be a commensal organism of the human skin $[1,7]$. To date, however, attempts to culture $K$. schroeteri from patients have been unsuccessful $[6,7]$. It is true habitat remains undiscovered. We are not sure whether the $K$. schroeteri pneumonia in our patient was a primary infection or a secondary manifestation of central line associated $K$. schroeteri bacteremia.

There have been 5 documented cases of $K$. schroeteri infection in patients with hematologic malignancies. In the other 4 patients reported in the literature with hematologic malignancies and $K$. schroeteri infection, the underlying malignancy was AML. All 5 patients had pulmonary infiltration, 4 patients had bacteremia, and 1 patient had skin manifestations. Four out of 5 reported patients died. All of the patients developed their infection after induction chemotherapy. We believe the central venous catheter placement in our patient had a role in the development of this infection. There are several other cases of $K$. schroeteri infection that prove the bacterium has a propensity to favor synthetic material as a site of infection $[1,5,6]$. Our patient likely developed a central line associated blood stream infection and eventual seeding of the pulmonary tissue leading to pneumonia. In addition, there is one case of community-acquired pneumonia in a patient who was immunosuppressed secondary to daily administration of $20 \mathrm{mg}$ of Prednisone. This patient developed bacteremia as well died from septic shock [8]. Given the presence of these 6 cases of pneumonia with bacteremia does not make it unreasonable to hypothesize that K. schroeteri has some adhesive properties that allow it to stick to the surface epithelium of the respiratory tract and cause patients to develop pneumonia in the appropriate clinical setting. In addition to the 6 cases of bacteremia and pneumonia, we have reviewed the literature and found 12 cases of implantable tissue related infections caused by $K$. schroeteri. These cases are detailed in Table 1.

$K$. schroeteri is an underrecognized and underreported organism. Hodiamont et al. reported on two cases of pneumonia and bacteremia caused by K. schroeteri [4]. In their research they came across six cases of pneumonia and bacteremia that were previously identified as Micrococcus sp. related. The discrepancies in those cases came from the fact that while the bacteria were identified as Micrococcus sp., they were resistant to penicillins. One of the important therapeutic properties of Micrococcus species is that they are inherently susceptible to penicillin and oxacillin [1]; however, Kytococcus species are not [1-6].

In conclusion, there are many factors involved in this case. The patient's underlying hematologic malignancy leading to prolonged neutropenia is likely the most important factor. In addition, the treatment with chemotherapy, history of splenectomy, and placement of a central venous catheter also likely contributed to the severity of infection in our patient. However, despite appropriate antibiotic therapy, the patient did not recover and eventually expired due to the infection. One of the unfortunate limitations in our case is the lack of sensitivity testing. We are not sure this would have changed the outcome in our patient due to the degree of overwhelming septic shock and multiorgan dysfunction; however, sensitivity testing may have impacted our treatment choices in this patient. Other cases outlined the use of different antibiotics including linezolid [3], doxycycline [5], amoxicillin [9], ofloxacin [10], and daptomycin [11]. However, vancomycin remains a common initial option due to the gram-positive nature of the organism.

Further studies should concentrate on the reason why prosthetic infections due to $K$. schroeteri are far less virulent compared to pneumonia and bacteremia. So far all 12 documented prosthetic tissue infections have resulted in no deaths, while 5 out 6 patients with pneumonia and bacteremia have died. The immunocompromised status of the 5 patients that died is likely the most important reason; however, this is difficult to confirm based on the dearth of case reports. At this point, it is not clear whether the immense immunocompromised status due to prolonged neutropenia played a role in a worse outcome or if it is due to unrecognized virulence factors of this organism.

\section{Conflict of Interests}

This paper received no funding or grants from commercial and noncommercial sources. There is no commercial funding or conflict of interests in this paper.

\section{Acknowledgments}

The authors would like to acknowledge Cindy Keyes, RN, and Beth Holtz, RN, for help with the preparation and proofreading of this paper. 


\section{References}

[1] K. Becker, P. Schumann, J. Wüllenweber et al., "Kytococcus schroeteri sp. nov., a novel Gram-positive actinobacterium isolated from a human clinical source," International Journal of Systematic and Evolutionary Microbiology, vol. 52, no. 5, pp. 1609-1614, 2002.

[2] A. R. Nagler, K. A. Wanat, M. A. Bachman et al., "Fatal Kytococcus schroeteri infection with crusted papules and distinctive histologic plump tetrads," Archives of Dermatology, vol. 147, no. 9, pp. 1119-1121, 2011.

[3] O. Blennow, K. Westling, I. Fröding, and V. Özenci, "Pneumonia and bacteremia due to Kytococcus schroeteri," Journal of Clinical Microbiology, vol. 50, no. 2, pp. 522-524, 2012.

[4] C. J. Hodiamont, C. Huisman, L. Spanjaard, and R. J. van Ketel, "Kytococcus schroeteri pneumonia in two patients with a hematological malignancy," Infection, vol. 38, no. 2, pp. 138-140, 2010.

[5] J. F. W. Chan, S. S. Y. Wong, S. S. M. Leung et al., "First report of chronic implant-related septic arthritis and osteomyelitis due to Kytococcus schroeteri and a review of human K. schroeteri infections," Infection, vol. 40, no. 5, pp. 567-573, 2012.

[6] C. Le Brun, J. Bouet, P. Gautier, J.-L. Avril, and O. Gaillot, "Kytococcus schroeteri Endocarditis," Emerging Infectious Diseases, vol. 11, no. 1, pp. 179-180, 2005.

[7] I. Szczerba and Z. Krzemisnki, "Occurrence and number of bacteria from the Micrococcus, Kocuria, Nesterenkonia, Kytococcus and Dermacoccus genera on skin and mucous membranes in humans," Medycyna Doświadczalna i Mikrobiologia, vol. 55, no. 1, pp. 67-74, 2002.

[8] I. Mohammedi, C. Berchiche, K. Becker et al., "Fatal Kytococcus schroeteri bacteremic pneumonia," Journal of Infection, vol. 51, no. 2, pp. ell-e13, 2005.

[9] A. Renvoise, V. Roux, F. Thuny, A. Riberi, and J.-P. Casalta, "Kytococcus schroeteri, a rare agent of endocarditis," International Journal of Infectious Diseases, vol. 12, no. 2, pp. 223-227, 2008.

[10] H. Jacquier, A. Allard, P. Richette, H. K. Ea, M. J. SansonLe Pors, and B. Berçot, "Postoperative spondylodiscitis due to Kytococcus schroeteri in a diabetic woman," Journal of Medical Microbiology, vol. 59, no. 1, pp. 127-129, 2010.

[11] J. C. Liu, D. R. Jenkins, H. Malnick, J. Kovac, and J. Szostek, "Kytococcus schroeteri endocarditis successfully managed with daptomycin: a case report and review of the literature," Journal of Medical Microbiology, vol. 61, no. 5, pp. 750-753, 2012.

[12] K. Becker, J. Wüllenweber, H.-J. Odenthal et al., "Prosthetic valve endocarditis due to Kytococcus schroeteri," Emerging Infectious Diseases, vol. 9, no. 11, pp. 1493-1495, 2003.

[13] B. Mnif, I. Boujelbène, F. Mahjoubi et al., "Endocarditis due to Kytococcus schroeteri: case report and review of the literature," Journal of Clinical Microbiology, vol. 44, no. 3, pp. 1187-1189, 2006.

[14] C. Aepinus, E. Adolph, C. von Eiff, A. Podbielski, and M. Petzsch, "Kytococcus schroeteri: a probably underdiagnosed pathogen involved in prosthetic valve endocarditis," Wiener Klinische Wochenschrift, vol. 120, no. 1-2, pp. 46-49, 2008.

[15] S. Jourdain, V. Y. Miendje Deyi, K. Musampa et al., "Kytococcus schroeteri infection of a ventriculoperitoneal shunt in a child," International Journal of Infectious Diseases, vol. 13, no. 4, pp. e153-e155, 2009.
[16] R. Poyet, C. Martinaud, F. Pons, P. Brisou, and R. Carlioz, "Kytococcus schroeteri infectious endocarditis," Medecine et Maladies Infectieuses, vol. 40, no. 1, pp. 51-53, 2010.

[17] T. Yousri, M. Hawari, R. Saad, and S. Langley, "Kytococcus schroeteri prosthetic valve endocarditis," BMJ Case Reports, vol. 2010, 2010.

[18] F. Schaumburg, C. Schmalstieg, B. Fiedler, A. Brentrup, H. Omran, and K. Becker, "A bumpy road to the diagnosis of a Kytococcus schroeteri shunt infection," Journal of Medical Microbiology, vol. 62, no. 1, pp. 165-168, 2013. 


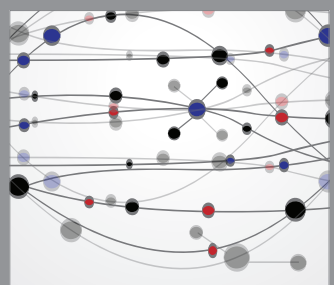

The Scientific World Journal
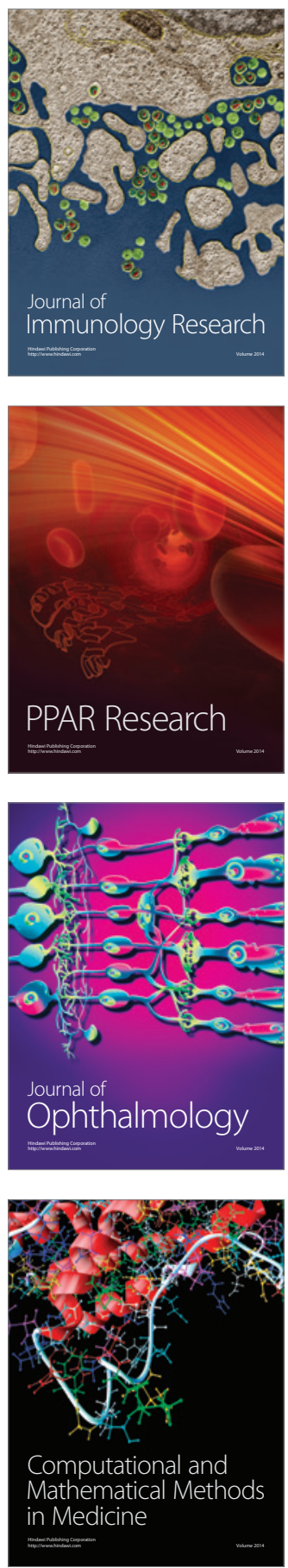

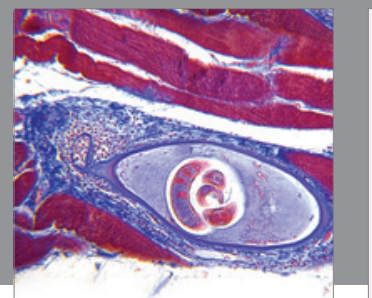

Gastroenterology

Research and Practice
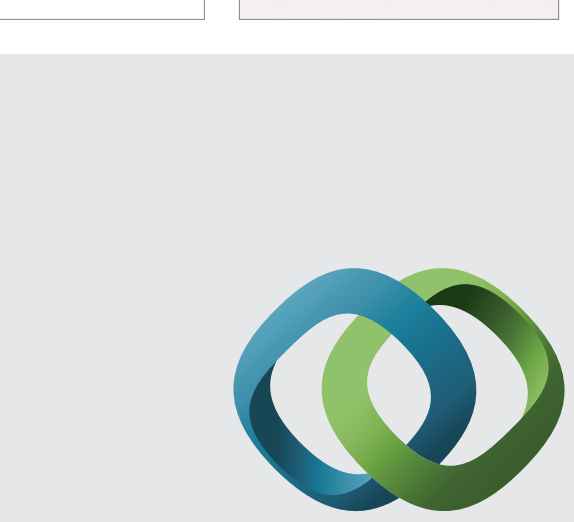

\section{Hindawi}

Submit your manuscripts at

http://www.hindawi.com
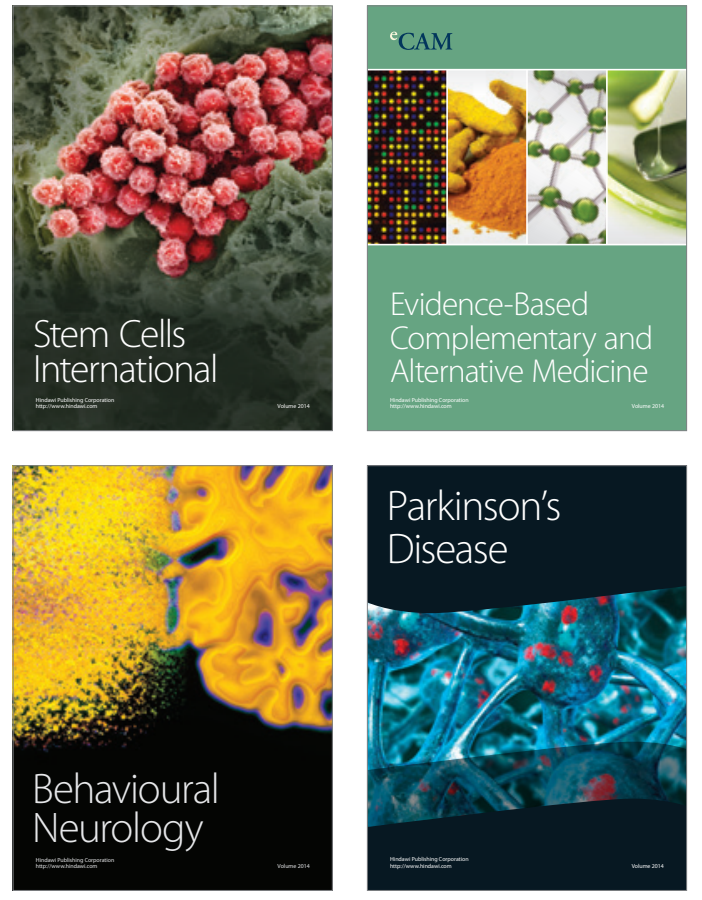
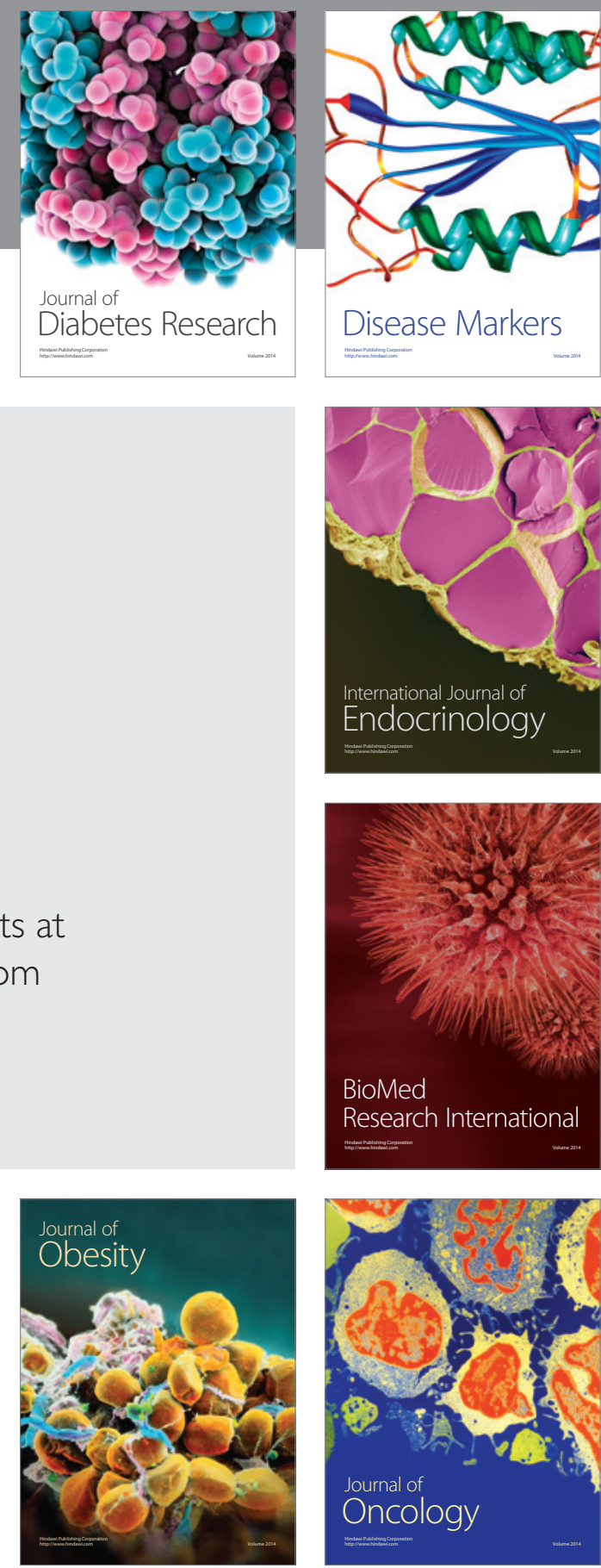

Disease Markers
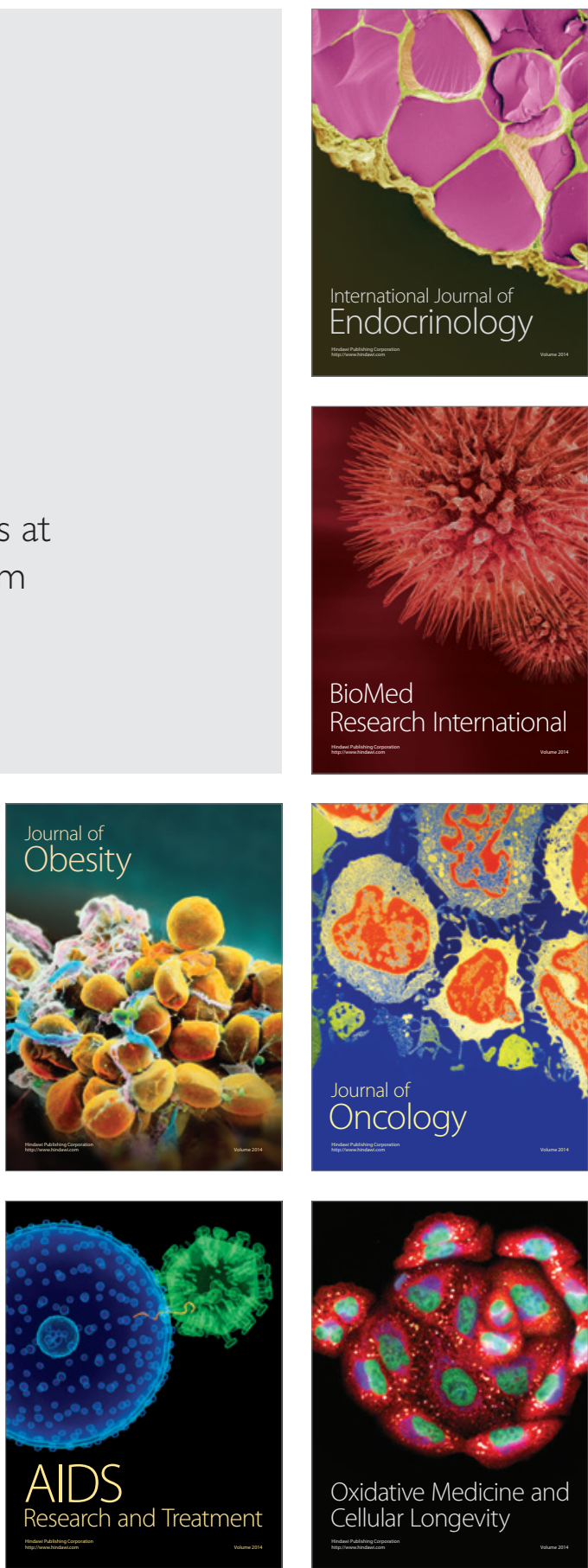